\title{
Examining Antecedents and Consequences of Gambling Passion: The Case of Gambling on Horse Races
}

\author{
Choong-Ki Lee ${ }^{1}$, Ki-Joon Back², David C. Hodgins ${ }^{3}$, and Tae Kyung Lee ${ }^{4 凶}$ \\ ${ }^{1}$ College of Hotel \& Tourism, Kyung Hee University, Seoul, Republic of Korea \\ ${ }^{2}$ Conrad N. Hilton College of Hotel and Restaurant Management, University of Houston, Houston, TX, USA \\ ${ }^{3}$ Department of Psychology, University of Calgary, Alberta, Canada \\ ${ }^{4}$ Department of Addiction Psychiatry, Seoul National Hospital, Seoul, Republic of Korea
}

Objective This study investigated the antecedents and consequences of gambling passion using structural equation modeling to examine relationships among gambling motivation, passion, emotion, and behavioral intentions in the horse racing industry.

Methods An onsite survey was conducted with 447 patrons at a horseracing park in South Korea. A confirmatory factor analysis showed that the Gambling Passion Scale was valid and reliable, resulting in two sub-scales: obsessive passion (OP) and harmonious passion (HP).

Results Study results indicated that extrinsic motivation influenced OP whereas intrinsic motivation significantly affected HP. Furthermore, OP was correlated with negative emotion, whereas HP was related to positive emotion. Gamblers' satisfaction was found to be influenced positively by positive emotion and negatively by negative emotion. Finally, satisfaction appeared to affect gamblers' behavioral intentions.

Conclusion Study results echoed the notion of distinct and separate gambling motivations and passions among horse racing gamblers. Furthermore, results identified specific areas to which horse racing operators or policy makers should pay special attention in developing effective marketing strategies to promote responsible gambling.

Psychiatry Investig 2013;10:365-372

Key Words Gambling passion, Motivation, Emotion, Satisfaction, Behavioral intentions, Horse racing gambling.

\section{INTRODUCTION}

Like many other jurisdictions, South Korea has legalized horseracing, casinos, cycle and motorboat racing, a lottery, and sports betting. Horseracing was legalized in 1962 to popularize and ensure the fair operation of races nationally and to promote the livestock industry. The Korea Racing Authority (KRA), a non-profit organization, is the sole racing authority in Korea and is supervised by the Ministry for Food, Agriculture and Fisheries. In 2009, overall attendance at racetracks reached 21.6 million, with betting sales exceeding US\$ 6.28 billion (net revenues: US $\$ 1.68$ billion). ${ }^{1}$ Due to the dramatic

\footnotetext{
Received: November 8, 2012 Revised: December 22, 2012

Accepted: January 15, 2013 Available online: December 16, 2013

$\triangle$ Correspondence: Tae Kyung Lee, MD, PhD

Department of Addiction Psychiatry, Seoul National Hospital, 398 Neungdong-

ro, Gwangjin-gu, Seoul 143-711, Republic of Korea

Tel: +82-2-2204-0179, Fax: +82-2-2204-0394

E-mail: TKLeeMD@gmail.com

(a) This is an Open Access article distributed under the terms of the Creative Commons Attribution Non-Commercial License (http://creativecommons.org/licenses/bync/3.0) which permits unrestricted non-commercial use, distribution, and reproduction in any medium, provided the original work is properly cited.
}

increase in horseracing's popularity among gamblers, policy makers, legislators, and experts have expressed concern about players' pathological gambling behaviors. According to Park et al. ${ }^{2} 23 \%$ of the pathological gamblers who participated in Korea's most recent prevalence survey indicated that horseracing was their favorite gambling activity, compared with only $4.4 \%$ of recreational gamblers.

Loroz $^{3}$ studied gambling motivation from the experiential consumption and psychological benefits perspectives. He insisted that different types of gamblers have different motivations to gamble. According to Lee et al. ${ }^{4}$ gambling-related motivations include the need to escape, socialize, and win, and to explore different facets of the recreation environment. Also, individuals' affective attachment to gambling behaviors varies. Rousseau et al. ${ }^{5}$ described two types of gambling passionharmonious passion (HP), which is associated with positive affective outcomes (e.g., excitement, arousal, fun), and obsessive passion (OP), which is associated with negative affective outcomes (e.g., guilty, anxiety, annoyance).$^{5-8}$

Although a great deal of research has identified gambling 
motivations and assessed levels of gambling affective attachment, no studies to date have identified the causal relationship among gambling motivation, passion, and emotional and behavioral outcomes. Thus, the main objective of this study was to assess the causal relationships between the antecedents and consequences of gambling passion.

\section{Conceptual background}

Vallerand et al. ${ }^{8,9}$ defined passion as a strong inclination toward an activity that people enjoy, find important, and in which they invest time and energy. They classified gambling passion into two sub-passions: obsessive and harmonious. Obsessive passion (OP) relates to the internal pressures that push individuals to become involved in an activity, ${ }^{8}$ while harmonious passion (HP) is associated with individuals' free choice to engage in an activity. ${ }^{5}$ Individuals with OP engage in activities that they find difficult to resist, and they experience conflict between the activity and obligations in their lives. In contrast, individuals with HP can control their activity and decide when to be involved, allowing harmony between the passionate activity and their lives.

Vallerand et al. ${ }^{8}$ suggested that different types of motivation were significantly associated with OP and HP. OP results from a controlled internalization of the event associated with the self-identity. A controlled internalization happens when a person feels an internal pressure between greatly valuing and enjoying an activity and feeling constrained from enjoying it due to numerous conditions linked to it. For instance, a person may believe that gambling is the only way to enhance economic status. If this is true, the gambling activity is no longer an alternative leisure activity, but is dictated by the desire for acceptance. ${ }^{6}$ This situation may be attributable to a lack of selfdetermined motivation (i.e., extrinsic motivation), eventually dominating self-identity and interfering with other activities in a person's regular life. ${ }^{5}$ Consistent with this, Vallerand et al. ${ }^{8}$ found that individuals who self-excluded themselves from casinos and self-identified as pathological gamblers showed greater OP and were more likely to describe their primary motivation for gambling as winning money than were recreational gamblers.

On the other hand, since HP stems from an individual's autonomous internalization of a behavior as one that is significantly valued by them, the motivation to engage in this specific behavior is strongly self-determined. ${ }^{8,10}$ Since the behavior is determined by individual autonomy, also known as intrinsic motivation, it involves a sense of volition and personal endorsement that does not dominate but keeps harmony with other aspect of a person's lifestyle. People who find gambling to be fun or enjoyable are likely to show that they are capable of balancing this activity with other types of activities in their lives. $^{8}$

Several studies have explored the consequences of gambling passion. ${ }^{5,7,811,38}$ The results of the Rousseau et al. ${ }^{5}$ study indicated that OP was positively related to negative consequences (i.e., ruminations, anxiety, and feelings of guilt), but these consequences were not significantly related with HP. On the other hand, OP was found to have negative correlation with positive consequences (i.e., vitality, concentration, and positive emotion), but none of these consequences were positively correlated with HP. Specifically, Mageau et al. ${ }^{6}$ also found that OP was generally associated with negative consequences such as feelings of guilt, anxiety, and negative emotion, whereas HP was associated with positive consequences such as amusement, fun, and positive emotion.

Numerous studies have considered emotional correlates of gambling behavior. In particular, many researchers have investigated the effects of mood on gambling motivation or other types of cognitive attitude toward the gambling activity. ${ }^{12-14}$ As Apter ${ }^{12}$ stated, the emotional aspects of gambling have been studied using a reversal theory that focuses on hedonic tone to explain both reinforcing and aversive aspects. Hills et al. ${ }^{14}$ supported the idea of using Forgars' affect infusion model ${ }^{15}$ in which prior mood has a significant effect on gambling persistence among recreational gamblers, while pathological gamblers appear to be motivated to gamble regardless of prior mood.

Although there is strong support for the effect of mood on gambling motivation and other cognitive and conative attitudes toward the gambling activity, there has been limited study of the effect of gambling motivation and passion on gambling emotion. Gambling emotion can be explained as the affective responses that arise when people use or consume products or services as a form of consumption emotion. ${ }^{16}$ Many researchers generally employ two dimensions of consumption emotion, positive and negative. Yoo et al. ${ }^{17}$ measured emotions with a positive feeling dimension, such as being excited, and a negative feeling dimension, such as being angry. Lee et al. ${ }^{18}$ studied attendees at a cultural music festival and found that festival visitors' satisfaction and behavioral intentions toward future participation were influenced positively by positive emotions and negatively by negative emotions. Also, Han and Back ${ }^{19}$ investigated two underlying dimensions of consumption emotion that had different levels of effect on satisfaction. A study by Lee et al. ${ }^{20}$ found that emotions had a significant impact on World Cup patron satisfaction. Furthermore, Liljander and Strandvik ${ }^{21}$ pointed out that positive emotion increased customer satisfaction, whereas negative emotion decreased satisfaction. This two-dimensional approach to emotion enables researchers to further understand the role of various types of consumption emotion in influencing satisfac- 
tion, particularly in the context of horseracing gambling behaviors. In the gambling context, negative gambling emotions include ruminations, anxiety, and feelings of guilt, whereas positive gambling emotions include vitality and concentration. ${ }^{7}$ Mageau et al. ${ }^{6}$ characterized positive gambling emotions as amusement and fun, while negative gambling emotions included feelings of guilt and anxiety.

The positive effect of consumer satisfaction on behavioral intention has been widely supported in tourism, gambling, and marketing research. ${ }^{18,20,22-26}$ Consumer satisfaction not only contributes to business turnover, but satisfied customers are more likely to recommend a product or service to other people. The literature suggests that satisfied recreational gamblers are more likely to revisit gambling sites (e.g., casino resort, horseracing park).

In sum, in this study we hypothesized that various types of motivations to engage in horseracing gambling were directly linked to two separate dimensions of gambling passion. Specifically, intrinsic motivation would have a significant effect on harmonious gambling passion due to its autonomous internalization. Since HP is related to a sense of volitional control over involvement in horseracing, it would be related to positive affect (e.g., fun) which would positively affect the customer's satisfaction level and further lead to positive behavioral intentions to participate in the future. Similarly, we hypothesized that extrinsic motivation would positively affect obsessive gambling passion due to being less self-determined. With regard to the loss of control over behavior, OP would be related to negative affect, which would be negatively associated with overall satisfaction with horseracing, acting to decrease future behavioral intentions.

\section{METHODS}

\section{Measures}

The study questionnaire was composed of three major parts. Prior to distribution, the questionnaire was translated into Korean using the back translation method. ${ }^{27}$ The measures were pilot-tested with customers and operators of horseracing games-further clarification was not found to be necessary beyond minor wording changes. The first part assessed behaviorally oriented gambling variables such as number of visits, amount of bets, and type of accompanying gamblers (e.g., family, friends). The second part measured motivations, gambling passion, gambling emotion, and behavioral intentions to engage in horseracing gambling. A 7-point Likert ( $1=$ strongly disagree; $7=$ strongly agree) scale was used to measure all indicators in part 2 . The final part examined the demographic characteristics of respondents.

Gambling passion was assessed using the Gambling Pas- sion Scale. ${ }^{5}$ The reliability and validity of the OP and HP subscales have been demonstrated to be satisfactory in the previous literature, ${ }^{5-7,28,29}$ including the Korean context. ${ }^{4,28}$ The OP scale includes five items (e.g., I cannot live without this gambling game); and the HP scale contains five items (e.g., gambling game allows me to live memorable experiences). Intrinsic and extrinsic gambling motivation was assessed with 10 items adopted from several literatures ${ }^{30,31}$ that reflected intrinsic (e.g., to enjoy) and extrinsic motivations (e.g., to hit a jackpot). ${ }^{9,32}$ Gambling emotions were assessed as consumption emotion, which can be described as the affective responses generated specifically during product usage or consumption experiences. ${ }^{16}$ Consumption emotion can be divided into two independent dimensions: positive and negative. Four items for positive emotions (e.g., happy, excited, thrilled) and six items for negative emotions (e.g., angry, sad, frustrated) were chosen based on previous research. ${ }^{19}$ Gambling satisfaction was measured by two items: "I feel satisfied with the service in this horseracing gambling," and "Overall, I am satisfied with this horseracing gambling." Gambling intentions were assessed by three items: "I will play this horseracing game again next time," "I will recommend this horseracing gambling to my friends," and "I will say positive things about this horseracing gambling to others." ${ }^{18,25}$

\section{Data collection}

To maximize the representativeness of the sample of horseracing gamblers, the survey was conducted with actual horseracing gamblers on Saturday and Sunday in the first and last weeks of December 2009. Questionnaires were administered during the races at a temporary booth in the horseracing track building. Participants either approached the booth voluntarily or were approached by field researchers who outlined the purpose of the study. Upon consenting, a self-administered questionnaire was presented to each respondent to complete. The questionnaires were completed in the presence of the field researchers, allowing for rigorous monitoring of the data collection process. Those who completed the survey questionnaire were given a small gift. Of the 447 questionnaires collected, 18 questionnaires were eliminated from the analysis due to missing data (3 questionnaires were incomplete and 15 were missing answers to important questions). Ultimately, 429 questionnaires were coded and used in the analysis.

\section{RESULTS}

\section{Profile of respondents}

Table 1 presents characteristics of the respondents. Participants were predominately male (74.1\%) and married (69.9\%) 
Table 1. Demographic characteristics of respondents $(\mathrm{N}=429)$

\begin{tabular}{|c|c|c|}
\hline Characteristic & Frequency & $\%$ \\
\hline \multicolumn{3}{|l|}{ Gender } \\
\hline Male & 317 & 74.1 \\
\hline Female & 111 & 25.9 \\
\hline \multicolumn{3}{|l|}{ Age } \\
\hline $20-29$ & 56 & 13.1 \\
\hline $30-39$ & 87 & 20.3 \\
\hline $40-49$ & 158 & 36.9 \\
\hline 50 and over & 127 & 29.7 \\
\hline \multicolumn{3}{|l|}{ Education } \\
\hline High school & 125 & 29.1 \\
\hline 2-year college & 86 & 20.5 \\
\hline 4-year college & 193 & 45.0 \\
\hline Graduate school & 23 & 5.4 \\
\hline \multicolumn{3}{|l|}{ Marital status } \\
\hline Single & 112 & 26.1 \\
\hline Married & 300 & 69.9 \\
\hline \multicolumn{3}{|c|}{ Monthly income (US\$) } \\
\hline Under 1000 & 51 & 12.1 \\
\hline $1000-1999$ & 79 & 18.7 \\
\hline 2000-3999 & 157 & 37.2 \\
\hline $4000-5999$ & 74 & 17.5 \\
\hline More than 6000 & 61 & 14.5 \\
\hline \multicolumn{3}{|c|}{ Frequency of annual visits } \\
\hline 20 or less & 182 & 42.5 \\
\hline $21-40$ & 96 & 22.4 \\
\hline $41-60$ & 77 & 18.0 \\
\hline $61-80$ & 22 & 5.1 \\
\hline $81-100$ & 32 & 7.5 \\
\hline $101-120$ & 11 & 2.6 \\
\hline 121 or over & 8 & 1.9 \\
\hline \multicolumn{3}{|l|}{ Visit companion } \\
\hline Alone & 114 & 26.6 \\
\hline Friends & 220 & 51.3 \\
\hline Family & 73 & 17.0 \\
\hline Group & 7 & 1.6 \\
\hline Others & 15 & 3.5 \\
\hline
\end{tabular}

and most were between 40 and 49 years of age (36.9\%) and 50 and over (29.7\%). About half of the respondents had university-level or higher education (50.4\%) and most reported monthly income between US\$2,000 and 3,999 (37.2\%). The majority of respondents visited the track 20 or fewer times (42.5\%) and they were typically accompanied by friends (51.3\%).

\section{Construct identification and validation}

Content validity ensures that the measure includes an adequate and representative set of items that would describe the concept. The lists of attributes for the study variables were selected after 1) an extensive literature review, 2) interviews with academics in the field of gambling, and 3) interviews with horseracing managers. All items were pilot-tested with customers and operators at the horseracing facility who were asked to evaluate the appropriateness of the measuring instruments. It was evident that these research procedures ensured high content validity of the measurement instrument.

Convergent validity was secured when all average variance extracted (AVE) exceeded the cutoff point of $0.50 .{ }^{33}$ Furthermore, discriminant validity exists when the AVE of each construct exceeds the square of the coefficient representing its correlation with other constructs, ${ }^{33}$ as shown in Table 2. For instance, the AVE of the HP construct (0.83) exceeded the square of the inter-correlation (shared variance) between gambling passion scale (HP) and intrinsic motivation (0.38).

\section{Modeling test}

Following Anderson and Gerbing's ${ }^{34}$ two-step approach, a measurement model was estimated prior to the structural model using confirmatory factor analysis (CFA). As shown in Table 3, the results for the measurements of multiple constructs were good: $\left[\chi^{2}(532)=2073.24, \chi^{2} / d f=3.90\right.$, root mean square error of approximation (RMSEA) $=0.08$, comparative fit index $(\mathrm{CFI})=0.94$, non-normed fit index $(\mathrm{NNFI})=0.93]$. All of the indicator loadings for constructs were significant $(\mathrm{p}<0.01)$. The CFA resulted in the 8 -factor model which was composed of two dimensions of gambling motivation (Extrinsic and Intrinsic), two dimensions of gambling passion scale (OP and HP), two dimensions of emotion (Positive and Negative), one dimension of satisfaction, and one dimension of behavioral intentions.

The hypothesized relationships among the factors shown in Figure 1 and the factor models described above were examined simultaneously using LISREL $8.75 .^{35}$ As Figure 1 indicates, the conceptual model included direct paths from exogenous variables; two dimensions of gambling motivation to the two dimensions of the Gambling Passion Scale (OP and $\mathrm{HP}$ ) were specified. Also, direct paths from the Gambling Passion Scale to emotion and the paths from each emotion to customer satisfaction as well as the paths from satisfaction to gambling behavioral intentions were specified in the model. To identify the best model for testing, a competing model was created. This model was the same as the conceptual model, except that the direct paths from each exogenous variable to behavioral intentions were included.

As shown in Figure 1, the overall fit of the conceptual mod- 
Table 2. Correlations, squared correlations, and AVE

\begin{tabular}{|c|c|c|c|c|c|c|c|c|c|}
\hline & EM & IM & $\mathrm{OP}$ & $\mathrm{HP}$ & $\mathrm{NE}$ & $\mathrm{PE}$ & CS & $\mathrm{BI}$ & AVE \\
\hline EM & 1.00 & & & & & & & & 0.73 \\
\hline IM & $\mathbf{0 . 3 4}(0.12)$ & 1.00 & & & & & & & 0.72 \\
\hline $\mathrm{OP}$ & $\mathbf{0 . 5 2}(0.27)$ & $\mathbf{0 . 3 7}(0.14)$ & 1.00 & & & & & & 0.82 \\
\hline HP & $\mathbf{0 . 3 4}(0.12)$ & $0.62(0.38)$ & $\mathbf{0 . 4 4}(0.19)$ & 1.00 & & & & & 0.83 \\
\hline $\mathrm{NE}$ & $\mathbf{0 . 3 9}(0.15)$ & $0.10(0.01)$ & $0.40(0.16)$ & $\mathbf{0 . 1 2}(0.01)$ & 1.00 & & & & 0.75 \\
\hline $\mathrm{PE}$ & $\mathbf{0 . 2 9}(0.08)$ & $\mathbf{0 . 6 1}(0.37)$ & $\mathbf{0 . 2 3}(0.05)$ & $\mathbf{0 . 5 2}(0.27)$ & $-0.10(0.01)$ & 1.00 & & & 0.85 \\
\hline CS & $0.06(0.00)$ & $\mathbf{0 . 2 0}(0.04)$ & $0.04(0.00)$ & $\mathbf{0 . 2 4}(0.06)$ & $-0.07(0.00)$ & $0.42(0.18)$ & 1.00 & & 0.70 \\
\hline BI & $\mathbf{0 . 1 2}(0.01)$ & $0.38(0.14)$ & $0.01(0.00)$ & $\mathbf{0 . 3 6}(0.13)$ & $-0.06(-0.00)$ & $0.25(0.06)$ & $0.38(0.14)$ & 1.00 & 0.73 \\
\hline Mean & 3.20 & 3.86 & 2.62 & 3.28 & 3.46 & 4.43 & 4.42 & 3.63 & \\
\hline Std. D & 1.48 & 1.24 & 1.36 & 1.36 & 1.26 & 1.19 & 1.44 & 1.40 & \\
\hline
\end{tabular}

Correlations in bold are significant at the either 0.01 level or 0.05 level (2-tailed). EM: extrinsic motivation, IM: intrinsic motivation, OP: obsessive passion, HP: harmonious passion, NE: negative emotion, PE: positive emotion, CS: customer satisfaction, BI: behavioral intentions, AVE: average variance extracted

el was good. Although the Chi-square was significant $(\mathrm{p}<$ 0.001 ), the CFI and NNFI were about 0.93 , respectively, and RMSEA was 0.08 , implying that the model was appropriate to test further. The overall fit of the competing model was inferior to that of the conceptual model. By constraining the direct effects of exogenous variables (gambling motivation) on endogenous variable (behavioral intentions) in the competing model, the statistical indicator of fit (chi-square) and practical indicators of fit (CFI and NNFI) did not significantly improve from the conceptual model $\left(\Delta \chi^{2}=15.78, \Delta d f=6, p>0.05\right)$. Thus, we confirmed the conceptual model as a rigorous model for further testing of the relationships.

\section{Parameter estimates}

Figure 1 presents the maximum-likelihood parameter estimates for the data. First, gambling motivations had a significant effect on the Gambling Passion Scale. Specifically, extrinsic motivation had significantly effects on obsessive gambling passion $\left(\gamma_{11}=0.57, \mathrm{t}=10.84\right)$, whereas intrinsic gambling motivation had significantly higher effects on harmonious gambling passion $\left(\gamma_{23}=0.75, t=13.06\right)$. As expected, obsessive gambling passion showed a significant effect on negative emotion $\left(\beta_{31}=0.48, \mathrm{t}=8.34\right)$, whereas harmonious passion had a significant effect on positive emotion $\left(\beta_{42}=0.61, t=9.01\right)$. Consistent with previous research, negative emotion had a negative effect and positive emotion has a positive effect on customer satisfaction $\left(\beta_{53}=-0.13, \mathrm{t}=-2.54 ; \beta_{54}=0.28, \mathrm{t}=4.95\right)$. Furthermore, study results supported those from previous research which showed that customer satisfaction had a positive effect on customers' behavioral intentions to participate in horseracing gambling in the future $\left(\beta_{65}=0.44, \mathrm{t}=6.64\right)$.

\section{DISCUSSION}

This research focused on different gambling motivations, passions, and emotions among horseracing gamblers in order to develop effective marketing strategies for promoting responsible gambling behaviors. We proposed a conceptual model that hypothesizes that extrinsic motivation has a significant predictive power for determining obsessive gambling passion and negative gambling emotion whereas intrinsic motivation has significant effects on harmonious gambling passion and positive emotion for horseracing gamblers. Positive emotion has significant positive effects on customer satisfaction which leads gamblers to favorable intentions to return to the horseracing track for gambling. In contrast, negative emotion decreases satisfaction, lowering intention to return.

Our study findings echoed the notion of distinctive separate antecedents and consequences of two dimensions of gambling passion. First, consistent with Deci's and Ryan's selfdetermination theory ${ }^{31}$ and Vallerand's studies, ${ }^{8}$ extrinsic motivation was significantly associated with OP. According to Ryan and Deci's ${ }^{10,31}$ self-determination theory and organismic integration theory, intrinsic motivation is determined by autonomy-thus, gamblers are more involved in a sense of volition and personal endorsement that does not dominate but rather harmonizes with other types of gambler lifestyles. Due to the lack of self-determined motivation, extrinsic motivation overpowers the gambler's self-identity and interferes with other activities, resulting in obsession with gambling behaviors. For instance, if a horseracing gambler's main motivation for participating in gambling is to win money, this can dictate a person's daily lifestyle and lead to obsession.

Second, two types of passion led to divergent gambling emotions about horseracing gambling during the activity en- 
gagement. Obsessive passion is caused by a lack of self-determined motivation and conscious choice, leading individuals to engage in gambling feeling angry, frustrated, and other negative emotions. In other words, negative emotions are driven by their obsessive passions. However, harmonious pas- sions are significantly associated with positive emotions in people who are autonomously engaged in the gambling activities.

Third, study results showed that customer satisfaction had significant mediating effects on the relationship between two

Table 3. Results of confirmatory factor analysis and reliability analysis*

\begin{tabular}{|c|c|c|c|c|}
\hline Construct & a & Attribute & Loading $(\lambda)^{\dagger}$ & t-value f $^{\ddagger}$ \\
\hline \multirow{4}{*}{ Extrinsic motivation } & 0.85 & To hit a jackpot & 0.77 & 16.98 \\
\hline & & To buy something that I want from earning of horseracing game & 0.76 & 15.42 \\
\hline & & To make money in a short period of time $\S$ & 0.93 & \\
\hline & & To win lots of money & 0.89 & 22.78 \\
\hline \multirow[t]{6}{*}{ Intrinsic motivation } & 0.84 & To be enjoyable & 0.87 & 20.03 \\
\hline & & To release tension & 0.70 & 16.06 \\
\hline & & To be thrilled & 0.78 & 18.41 \\
\hline & & To learn a new game & 0.70 & 15.77 \\
\hline & & To settle down feeling & 0.70 & 15.00 \\
\hline & & To be excited $\S$ & 0.88 & \\
\hline \multirow[t]{5}{*}{ Obsessive passion } & 0.90 & I cannot live without this gambling game $\S$ & 0.87 & \\
\hline & & I am emotionally dependent on this gambling game & 0.83 & 21.16 \\
\hline & & I have tough time controlling my need to gamble at this game & 0.86 & 23.78 \\
\hline & & I have almost obsessive feeling for this gambling game & 0.84 & 23.20 \\
\hline & & The urge is so strong, I cannot help myself from playing this gambling game & 0.80 & 21.60 \\
\hline \multirow[t]{5}{*}{ Harmonious passion } & 0.89 & This game allows me to live memorable experiences $\S$ & 0.83 & \\
\hline & & This gambling game is in harmony with the other activities inmy life & 0.83 & 20.52 \\
\hline & & $\begin{array}{l}\text { The new things that I discover with this gambling game allowme to appreciate } \\
\text { it even more }\end{array}$ & 0.86 & 21.73 \\
\hline & & This gambling game reflects the qualities I like about myself & 0.84 & 20.99 \\
\hline & & This gambling game allows me to live a variety of experiences & 0.80 & 19.40 \\
\hline \multirow[t]{6}{*}{ Negative emotion } & 0.84 & Unfulfilled§ & 0.75 & \\
\hline & & Discontented & 0.84 & 20.93 \\
\hline & & Frustrated & 0.86 & 21.90 \\
\hline & & Irritated & 0.86 & 21.93 \\
\hline & & Angry & 0.81 & 19.94 \\
\hline & & Sad & 0.70 & 15.19 \\
\hline \multirow[t]{4}{*}{ Positive emotion } & 0.81 & Happy§ & 0.85 & \\
\hline & & Excited & 0.84 & 20.41 \\
\hline & & Enthusiastic & 0.75 & 17.42 \\
\hline & & Thrilled & 0.80 & 18.77 \\
\hline \multirow[t]{2}{*}{ Customer satisfaction } & 0.89 & I feel satisfied with the service in this horseracing gambling & 0.91 & 19.78 \\
\hline & & Overall, I am satisfied with this horseracing gambling§ & 0.93 & \\
\hline \multirow[t]{3}{*}{ Behavioral intentions } & 0.76 & I will play this horseracing gambling again next time & 0.86 & 20.98 \\
\hline & & I will recommend this horseracing gambling to my friends & 0.87 & 21.30 \\
\hline & & I will say positive things about this horseracing gambling to others§ & 0.95 & \\
\hline
\end{tabular}

*fit indices: $\chi^{2}(532)=2073.24, \chi^{2} / d f=3.90$, Root Mean Square Error of Approximation=0.08, Comparative Fit Index=0.94, Non-Normed Fit In$\mathrm{dex}=0.93$, ${ }^{\dagger}$ standardized loading estimates, łbased on two-tailed tests; for $\mathrm{t}$-values greater than $1.96, \mathrm{p}<0.05$, $\$$ parameter fixed at 1.0 for the maximum-likelihood estimation. Thus, $\mathrm{t}$-values were not obtained for those fixed 
Figure 1. Results of structural equation modeling analysis. $\chi^{2}(552)=2416.91, p=$ 0.00 ; Root Mean Square Error of Approximation $=0.08$, Comparative Fit Index=0.93, Non-Normed Fit Index $=0.93$; $R^{2}(\mathrm{OP})=0.56 ; \mathrm{R}^{2}(\mathrm{HP})=0.33 ; \mathrm{R}^{2}(\mathrm{NE})=$ $0.23 ; R^{2}(P E)=0.38 ; R^{2}(C S)=0.10 ; R^{2}$ $(B I)=0.19$. All path coefficients were significant at $p=0.01$. Parenthesis indicates t-value. HP: harmonious passion, OP: obsessive passion, CS: customer satisfaction, PE: positive emotion, NE: negative emotion, Bl: behavioral intensions.

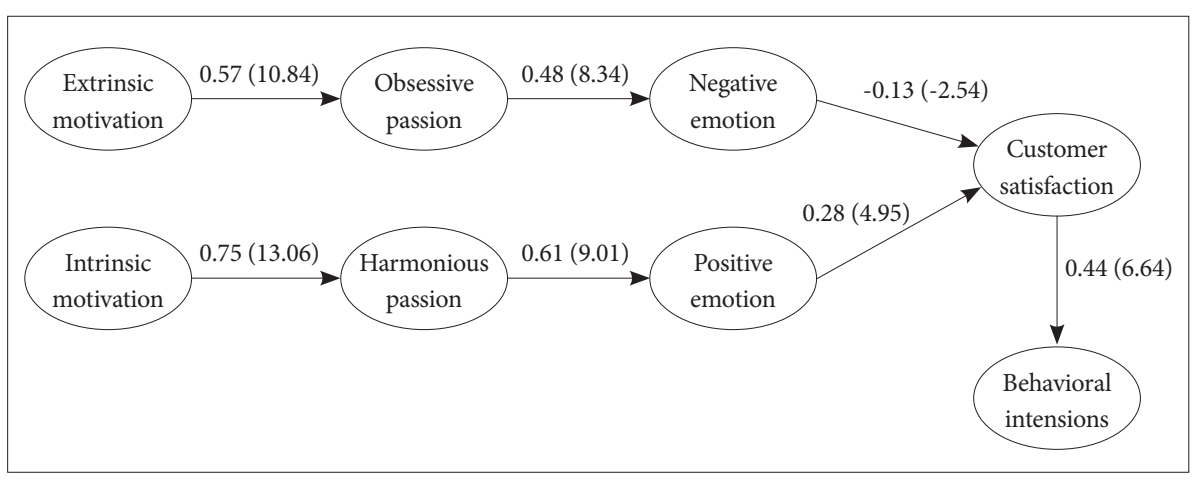

types of emotion and revisit intentions. This result was consistent with findings from previous research. ${ }^{19,36}$ Also, the result indicated that positive emotion had a stronger effect than negative emotion on satisfaction. Thus, for practitioners, fulfilling emotion factors through a closer investigation of customers' intricate emotional experiences is recommended to intensify satisfaction levels and revisit intentions. Horseracing facility operators should enhance significant attributes (e.g., food, service, or atmosphere) to elicit a higher level of positive emotional states.

In conclusion, this study explored the causal relationships among study variables in horseracing gambling behavior. From a theoretical perspective, findings extend our understanding of two types of gambling passions and their relationship with antecedents and consequences for people involved with horseracing gambling. This study has special value in that the data were collected at an actual horseracing gambling facility while participants/gamblers were involved in actual gambling activities. In addition, findings revealed that horseracing marketers should develop marketing materials that promote responsible gambling, focusing more on excitement rather than winning a big fortune. The research identified specific areas to which gambling operators or policy makers should pay special attention as they develop effective marketing strategies to promote responsible gambling. For example, horseracing advertisements should expressly indicate that gambling activities are enjoyable rather than potential avenues to changes in social status. Some jurisdictions do not specifically regulate gambling advertisements. In too many instances, advertising misguides the general public into believing that participating in gambling is one way to change their economic status.

Furthermore, horseracing gambling management could develop promotional materials that provide incentives to limit gambling participation rather than rewarding customers who spend significant time and money on gambling activities. Thus, visionary operators and regulators allow them to focus on promoting responsible gambling behaviors and minimizing the adverse social impacts of gambling on society.
This study had several limitations. First, the results may not be generalized to other jurisdictions. Data were collected from customers at a single horseracing gambling facility in Korea. Due to the delimited market segment and culture, implications should be carefully considered for other gambling properties, segments, and/or countries. Future studies should consider including different types of gambling activities (e.g., online and casino gambling) to better understand the study population. However, since the major portion of this study's results were consistent with those from previous studies, it would be worthwhile to conduct cross-cultural/cross-sectional studies. Second, since this study used only self-report measures, there may be a possible threat of common method variance. According to Campbell and Fiske, ${ }^{37}$ common method variance may be observed across measures of different constructs assessed using the same method. Although the threat may be minimal in our current study setting due to the rigorous measurement development and data collection procedure, multi-method processes are recommended in future studies. Future studies should also move from cross-sectional to longitudinal designs. Finally, actual gambling behavior dimensions (i.e., gambling time, money lost or won) should be measured in future studies.

\section{REFERENCES}

1. The National Gambling Control Commission. Available at: http:// www.ngcc.go.kr/Board/ReadView.do?idx=pds\&page=3\&no=8822. Accessed December 21, 2012.

2. Park S, Cho MJ, Jeon HJ, Lee HW, Bae JN, Park JI, et al. Prevalence, clinical correlations, comorbidities, and suicidal tendencies in pathological Korean gamblers: results from the Korean Epidemiologic Catchment Area Study. Soc Psychiatr Psychiatr Epidemiol 2010;45:621-629.

3. Loroz PS. Golden-age gambling: Psychological benefits and self-concept dynamics in aging consumers' consumption experiences. Psychol Market 2004;21:323-349.

4. Lee CK, Lee BK, Bernhard BJ, Lee TK. A comparative study of involvement and motivation among casino gamblers. Psychiatry Investig 2009; 6:141-149.

5. Rousseau FL, Vallerand RJ, Ratelle CF, Mageau GA, Provencher PJ. Passion and gambling: on the validation of the Gambling Passion Scale (GPS). J Gambl Stud 2002;18:45-66.

6. Mageau GA, Vallerand RJ, Rousseau FL, Ratelle CF, Provencher PJ. Passion and gambling: investigating the divergent affective and cognitive 
consequences of gambling. J Appl Soc Psychol 2005;35:100-118.

7. Ratelle CF, Vallerand RJ, Mageau GA, Rousseau FL, Provencher P. When passion leads to problematic outcomes: A look at gambling. J Gambl Stud 2004;20:105-119.

8. Vallerand RJ, Blanchard C, Mageau GA, Koestner R, Latelle C, Leonardo $\mathrm{M}$, et al. Les passions delame: on obsessive and harmonious passion. J Pers Soc Psychol 2003;85:756-767.

9. Vallerand RJ, Thill EE. Introduction au Concept de la Motivation. In: Dans RJ, Vallerand RJ, Thill EE, Editors. Introduction a la Psychologie de la Motivation. Quebec: Etudes Vivantes, 1993, p.3-40.

10. Ryan RM, Deci EL. Self-determination theory and the facilitation of intrinsic motivation, social development, and well-being. Am Psychol 2000;55:68-78.

11. Skitch SA, Hodgins DC. A passion for the game: problem gambling and passion among university students. Can J Behav Sci 2005;37:193197.

12. Apter MJ. Reversal theory: Motivation, Emotion and Personality. London: Routledge; 1989.

13. Dickerson M, Hinchy J, Legg England S. Minimal treatments and problem gamblers: a preliminary investigation. J Gambl Stud 1990;6:87-102.

14. Hills AM, Hill S, Mamone N, Dickerson M. Induced mood and persistence at gaming. Addiction 2001;96:1629-1638.

15. Forgas JP. Mood and judgment: the affect infusion model (AIM). Psychol Bull 1995;117:39-66.

16. Havlena WJ, Holbrook MB. The varieties of consumption experience: comparing two typologies of emotion in consumer behavior. J Consum Res 1986;13:394-404.

17. Yoo C, Park J, MacInnis DJ. Effects of store characteristics and in-store emotional experiences on store attitude. J Bus Res 1998;42:253-263.

18. Lee YK, Lee CK, Lee SK, Babin BJ. Festivalscapes and patrons' emotions, satisfaction, and loyalty. J Bus Res 2008;61:56-64.

19. Han HS, Back KJ. Assessing customers' emotional experiences influencing their satisfaction in the lodging industry. J Trav Tourism Market 2007;23:43-56.

20. Lee CK, Lee YK, Lee BK. Korea’s destination image formed by the 2002 World Cup. Ann Tourism Res 2005;32:839-858.

21. Liljander V, Strandvik T. Emotions in service satisfaction. Int J Serv Ind Manag 1997;8:148-169.

22. Appiah-Adu K, Fyall A, Singh S. Marketing culture and customer retention in the tourism industry. Serv Indust J 2000;20:95-113.
23. Bigne JE, Sanchez MI, Sanchez J. Tourism image, evaluation variables and after purchase behaviour: inter-relationship. Tourism Manag 2001; 22:607-616.

24. Oliver RL. A cognitive model of the antecedents and consequences of satisfaction decisions. J Market Res 1980;17:460-469.

25. Seo H, Lee CK, Lee YK. The effect of perceived values on visitor's satisfaction, revisit intention, and recommendation: Case of visitors to Kangwon Land casino. Korean J Hosp Adm 2008;17:181-195.

26. Wang Y, Lo HP, Chi R, Yang Y. An integrated framework for customer value and customer-relationship-management performance: a customer-based perspective from China. Manag Serv Qual 2004;14:169-182.

27. Mount DJ, Back KJ. A factor-analytic study of communication satisfaction in the lodging industry. J Hospit Tourism Res 1999;23:401-418.

28. Kim YH, Lee YH. Study on reliability and validity of gambling passion scale. Kor J Clin Psychol 2004;23:999-1009.

29. Wang CC, Chu YS. Harmonious passion and obsessive passion in playing online games. Soc Behav Pers 2007;35:997-1006.

30. Chantal Y, Vallerand RJ, Vallieres EF. Construction et validation de léchelle de motivation relative aux jeux de hasard et dargent: Jeux de hasard et d’argent. Loisir \& Société 1995;17:189-212.

31. Deci EL, Ryan RM. Intrinsic Motivation and Self-Determination in Human Behavior. New York: Plenum Publishing Co.; 1985.

32. Chantal Y, Vallerand RJ, Vallieres EF. Motivation and gambling involvement. J Soc Psychol 1995;135:755-763.

33. Fornell C, Larcker DF. Evaluating structural equation models with unobservable variables and measurement error. J Market Res 1981;18:3950.

34. Anderson JC, Gerbing DW. Structural equation modeling in practice: A review and recommended two-step approach. Psychol Bull 1988;103: 411-423.

35. Jöreskog KG, Sörbom D. LISREL 8.54. Analysis of Linear Structural Relations by the Method of Maximum Likelihood. Mooresville, IN: Scientific software; 2003.

36. Phillips DM, Baumgartner H. The role of consumption emotions in the satisfaction response. J Consum Psychol 2002;12:243-252.

37. Campbell DT, Fiske DW. Convergent and discriminant validation by the multitrait-multimethod matrix. Psychol Bull 1959;56:81-105.

38. Back KJ, Lee CK, Stinchfield R. Gambling motivation and passion: a comparison study of recreational and pathological gamblers. J Gamb Stud 2011; 27:355-370. 